\title{
Research on the influence of entrepreneurship inheritance and innovation and entrepreneurship team growth on sustainable economic development from the perspective of psychological contract
}

\author{
Zhang $\mathrm{li}^{1}$, Gengsujuan ${ }^{2, *}$ \\ ${ }^{1,2}$ School of Economics Harbin University of Commerce Heilongjiang Harbin
}

\begin{abstract}
The sustainable development of economy has always been the focus of society. Based on the data of some small and medium-sized enterprises in the new over the counter market from 2014 to 2018, this paper studies the relationship among entrepreneurship, psychological contract and the growth of innovation and entrepreneurship team. The empirical research shows that: the inheritance of entrepreneurship and the strengthening of psychological contract can promote the growth of innovation and entrepreneurship.When the psychological contract is strengthened, the entrepreneurship will also be inherited, and promoting the sustainable development of economy.
\end{abstract}

\section{INTRODUCTION}

The entrepreneurship of innovation and entrepreneurship teams can not be simply equated with individual entrepreneurship. From the perspective of enterprise growth, innovation and entrepreneurship teams retain the characteristics of individual entrepreneurship, and realize the expansion of entrepreneurship from individual level to organizational level. Therefore, it is necessary to analyze the characteristics of entrepreneurship within the innovation and entrepreneurship team, give full play to the role of entrepreneurship, strengthen the management of team entrepreneurship, and play a cultural leading and boosting role in the healthy growth of the innovation and entrepreneurship team.

\section{THEORETICAL ANALYSIS AND HYPOTHESIS}

The innovation and entrepreneurship team is a special team. Zhu Renhong . (2012) defined the innovation and entrepreneurship team as a special team composed of two or more people who share a common vision and goals, jointly establish a new enterprise or participate in the management of a new enterprise, have a certain equity and directly participate in strategic decision-making [1].Pan $\mathrm{Li}$ (2020) proposed that psychological contract is a psychological bridge between employees and enterprises[2]. Mao Lianghu (2020) defines entrepreneurship as a kind of innovation ability, entrepreneurial ability, growth ability and financial ability possessed by entrepreneurs in the development of enterprises [3]. According to the above theoretical analysis, the hypothesis is put forward

$\mathrm{H} 1$ : entrepreneurship can significantly promote the growth of innovation and entrepreneurship team.

$\mathrm{H} 2$ : the strengthening of psychological contract can positively promote the growth of innovation and entrepreneurship team and the inheritance of entrepreneurship.

H3: the strengthening of psychological contract and entrepreneurship promote the growth of innovation and entrepreneurship team, but the effect of entrepreneurship is better.

\section{Research design}

\subsection{Data sources}

Select the enterprises of "the new over the counter market" from 2014 to 2018 to study. In order to improve the authenticity and reference of the research, the samples of ST (special treatment) enterprises, enterprises that stopped transferring more frequently in five years, those with serious lack of data and those that did not publish annual reports in five years were eliminated. The selection of data is from CSMAR, and some missing data is manually collected by the National SME transfer system.

\footnotetext{
*Corresponding author: gengsujuan1997@163.com
} 


\subsection{Setting and description of variables}

\subsubsection{Construction of Entrepreneurship Index}

Referring to the research results of Zuoyi Ye and Wenbin $\mathrm{Wu}$ (2018), the entrepreneurship index is constructed by using five indicators of fixed assets per capital, intangible assets per capital, R \& D expenditure, independence of the board and per capital operating income[4]. Per capital fixed assets, per capital intangible assets and per capital operating income can show the entrepreneur's management capacity. The independence of the board of directors ultimately depends on whether the legal representative and the general manager of the company are integrated. R\&D expenditure is used as the proxy variable of internal innovation power.In order to make the entrepreneurship index more objective and convincing, this paper uses entropy weight method to quantify the entrepreneurship index.The first step of entropy weight method is to standardize the data. Suppose $\mathrm{K}$ indexes are given , $X_{1}, X_{2}, \ldots, X_{\mathrm{k}}, X_{i}=\left\{x_{1}, x_{2}, \ldots, x_{k}\right\}$.Suppose that the standardized value of each index data is $Y_{1}, Y_{2}, \ldots, Y_{k}$, then $Y_{i j}=\frac{X_{i j}-\min \left(X_{i}\right)}{\max \left(X_{i}\right)-\min \left(X_{i}\right)}$. The second step is to find the information entropy of each index. Entropy of a set of data : $E_{j}=-\ln (n)^{-1} \sum_{i=1}^{n} P_{i j} \ln P_{i j}, P_{i j}=Y_{i j} / \sum_{i=1}^{n} Y_{i j}$.If $P_{i j}=0$, then define $\lim _{P_{i j}=0} P_{i j} \ln P_{i j}=0$, The third step: determine the weight of each index. The weight of each index is calculated by information entropy $W_{i}=\frac{1-E_{i}}{k-\sum E_{i}} \quad(\mathrm{i}=1,2, \ldots, \mathrm{k})$.Based on the software Rstudio, the function is established, and the final weight is calculated. The entrepreneurship index is calculated by the sum of the standardized value of each index and the corresponding weight $E=w_{1} F I X+w_{2} I N T+w_{3} R E V+w_{4} B O A R D+w_{5} R \& D$.

\subsection{2 innovation and entrepreneurship team growth index measurement}

Enterprise growth refers to the data of Zhang Liucheng (2020) [5], which is measured by the "growth rate of net assets" of the enterprise. This index can reflect the income growth level of shareholders' equity, and then evaluate the growth of the enterprise by evaluating the growth rate of net assets. The evaluation index of enterprise growth is the growth rate of net assets, and the calculation method is the growth rate of net assets $=$ (net assets at the end of the period - net assets at the beginning of the period) / net assets at the beginning of the period.

\subsubsection{Measurement of psychological contract}

Because the salary satisfaction can directly show the psychological contract of employees to the enterprise, we can use the employee compensation payable index to measure the psychological contract.

\section{THE CONSTRUCTION OF MODEL}

In order to verify the hypothesis, the following model is established. In order to avoid pseudo regression, unit root test is performed for each variable in section data. The unit root test is carried out by rstudio software, and the $p$ value is far less than 0.05 . Therefore, the alternative hypothesis is accepted, that is, all variables are stable.The model are

$$
\begin{gathered}
N A G R=c+\alpha \ln E+\ln C O N+\mu \\
N A G R=c+\beta \ln \text { salary }+\ln C O N+\mu \\
E=c+\beta_{0} \ln \text { salary }+\ln C O N+\mu
\end{gathered}
$$

$N A G R=c+\beta_{1} \ln E+\beta_{2} \ln$ salary $+\ln C O N+\mu \mathrm{Am}$ ong them, nagr is the growth rate of net assets, which measures the growth of enterprises; $\mathrm{E}$ is the entrepreneurship index;Salary measure psychological contract; Con is the control variable, $\mathrm{C}$ is the intercept term.

\section{EMPIRICAL ANALYSIS}

Test H1, it can be seen from table 1 that the adjusted value is $0.37, \mathrm{P}$ values are less than 0.01 , indicating that the hypothesis is true. When the change of entrepreneurship is $1 \%$, the change of enterprise growth is $128.576 \%$, which indicates that entrepreneurship plays

\begin{tabular}{|c|c|c|c|c|c|}
\hline Variable & \multicolumn{2}{|c|}{ Entrepreneurship } & \multirow{2}{*}{$\begin{array}{c}\begin{array}{c}\text { psychological } \\
\text { contract }\end{array} \\
-65.8002 * * * \\
(-14.3143)\end{array}$} & \multirow{2}{*}{$\begin{array}{c}\begin{array}{c}\text { psychological } \\
\text { contract and }\end{array} \\
\text { Entrepreneurship } \\
\begin{array}{c}-56.2112^{* * *} \\
(-11.6054)\end{array}\end{array}$} & \multirow{2}{*}{$\begin{array}{c}\begin{array}{c}\text { psychological } \\
\text { contract on } \\
\text { Entrepreneurship }\end{array} \\
-0.0736^{* * *} \\
(-9.7085)\end{array}$} \\
\hline $\mathrm{C}$ & $\begin{array}{c}-55.0222 * * * \\
(-11.4943)\end{array}$ & $\begin{array}{c}0.0797 \\
(0.2264)\end{array}$ & & & \\
\hline $\mathrm{E}$ & $\begin{array}{c}128.576 * * * \\
(5.2330)\end{array}$ & $\begin{array}{c}163.0591 * * * \\
(6.3556)\end{array}$ & & $\begin{array}{c}130.2732 * * * \\
(5.3029)\end{array}$ & \\
\hline
\end{tabular}
a greater role in promoting the growth of enterprises.

Table 1. Regression results of the model 


\begin{tabular}{|c|c|c|c|c|c|}
\hline Salary & & & $\begin{array}{c}0.1670 \\
(1.2701)\end{array}$ & $\begin{array}{c}0.1977 \\
(1.5365)\end{array}$ & $\begin{array}{c}0.0002 \\
(1.0858)\end{array}$ \\
\hline CON1 & $\begin{array}{c}2.6680 * * * \\
(8.2525)\end{array}$ & & $\begin{array}{l}3.4672 * * * \\
(11.9835)\end{array}$ & $\begin{array}{c}2.6309 * * * \\
(8.1245)\end{array}$ & $\begin{array}{l}0.0064 * * * \\
(13.4530)\end{array}$ \\
\hline CON2 & $\begin{array}{c}-0.8058 * * * \\
(-3.0768)\end{array}$ & & $\begin{array}{c}-0.5507 * * \\
(-2.093)\end{array}$ & $\begin{array}{l}-0.8528 * * \\
(-3.2381)\end{array}$ & $\begin{array}{c}0.0023 * * * \\
(5.3448)\end{array}$ \\
\hline CON3 & $\begin{array}{c}1.3888 * * * \\
(5.4581)\end{array}$ & & $\begin{array}{c}0.6305 * * * \\
(2.3760)\end{array}$ & $\begin{array}{c}1.2045^{* * *} \\
(4.2856)\end{array}$ & $\begin{array}{l}-0.0044 * * * \\
(-10.0675)\end{array}$ \\
\hline Adjusted- $\mathrm{R}^{2}$ & 0.372819 & 0.062989 & 0.3451 & 0.3743 & 0.2666 \\
\hline F & 88.0850 & 40.3931 & 78.2065 & 71.105 & 54.2661 \\
\hline $\mathrm{p}$ & 0.0000 & 0.0000 & 0.0000 & 0.0000 & 0.0000 \\
\hline
\end{tabular}

Note: The values outside the brackets are the estimated coefficients, and the values inside the brackets are the $\mathrm{T}$ values of the estimated coefficients. Among them, $* * * *$, and $* *$ are significant at the levels of $1 \%, 5 \%$, and $10 \%$, respectively.

Test $\mathrm{H} 2$, it can be seen from table 1 that the adjusted value is 0.3451 , and the $\mathrm{p}$ value is far less than 0.01 , indicating that the hypothesis is true, that is, the strengthening of psychological contract can positively promote the growth of innovation and entrepreneurship team. The estimated coefficient of psychological contract is about 0.167 , which is greater than zero, proving that $\mathrm{H} 2$ is valid. When the change of psychological contract is $1 \%$, the change of enterprise growth is $0.167 \%$. Test $\mathrm{H} 2$, the adjusted value is 0.2666 , the goodness of fit of the model is acceptable. The value of $\mathrm{P}$ is much less than 0.01 , indicating that the hypothesis is true. The estimated coefficient of psychological contract is 0.0002 , which is greater than zero, indicating that psychological contract has a positive impact on the inheritance of entrepreneurship. Test H3, the adjusted value is $0.3743, \mathrm{P}$ value is far less than 0.01 , indicating that the hypothesis is true. And the change of entrepreneurship index leads to the change of innovation and entrepreneurship team growth is larger than the change of psychological contract.

\subsection{Robustness test}

According to table 1, the third column is the influence of entrepreneurship on the growth of innovation and entrepreneurship team without control variables. Compared with the second column of data, we can see that when there are control variables, the impact of entrepreneurship on team growth is significant, and the estimated coefficient is positive; When there is no control variable, the impact of entrepreneurship index on team growth is still significant, and the estimated coefficient is still positive. In the regression of other models, it is found that the introduction of control variables or not does not affect the positive and negative of the estimation coefficient of explanatory variables. Due to the limited space of the article, the situation of other models is not listed. Therefore, the model established in this paper is more robust.

\subsection{Conclusions and suggestions}

The results are as follows: 1. Entrepreneurship can significantly promote the growth of innovation and entrepreneurship team, and improving the team's innovation spirit, entrepreneurship and management ability can effectively promote the growth of innovation and entrepreneurship team. Per capital R\&D expenditure shows the enterprise's innovation spirit. No matter in which stage, the role of innovation spirit on enterprise growth is indispensable. 2. The strengthening of psychological contract can positively promote the growth of innovation and entrepreneurship team and the inheritance of entrepreneurship. One of the manifestations of strengthening psychological contract is that employees have a stronger sense of trust in the organization, and the salary or benefits can roughly meet the expectations of the organization. 3. The strengthening of psychological contract and entrepreneurship jointly promote the growth of innovation and entrepreneurship team, but the effect of entrepreneurship on team growth is better.

According to the above conclusions, entrepreneurship has a greater impact on the growth of enterprises than psychological contract

First, the government should continue to strengthen the cultivation of entrepreneurship, especially for small and medium-sized micro entrepreneurs. The government's support can help the growth of small and medium-sized micro enterprises in the first time and more accurately. Second, the managers of innovation and entrepreneurship team should enhance their entrepreneurship. In the initial stage of innovation and entrepreneurship, we should focus on cultivating our own innovation spirit and entrepreneurship. Third, we should make more effective internal promotion system, improve employees' salary and welfare, and strengthen psychological contract. The strengthening of psychological contract will enhance the team members' recognition of team leaders, generate admiration, and promote the horizontal transmission and vertical inheritance of individual entrepreneurship of leaders. The inheritance of entrepreneurship also promotes the growth of enterprises and the sustainable development of economy. 


\section{Reference:}

1. Zhu Renhong, Zeng Chuhong, Dai Jilin. Review and Prospect of entrepreneurial team research [J]. Foreign economy and management, 2012,34 (11): 11-18

2. Pan Li. Difficulties and solutions of grassroots HR in small and medium-sized enterprises from the perspective of psychological contract [J]. Enterprise science and technology and development, 2020 (12): $158-160$

3. Mao Lianghu, Li Huanhuan, Yang YeFan, Liu ran. Construction of entrepreneurship evaluation system based on entropy method [J]. Statistics and decision, 2020,36 (06): 156-160

4. Ye Zuoyi, Wu Wenbin. Analysis on the driving factors of enterprise R \&amp; D Investment -- Based on the perspective of entrepreneurship of Chinese Listed Companies [J]. Journal of Shanghai University of international business and economics, 2018,25 (02): 40-51 + 86

5. Zhang Liu Cheng, Xia Ping. Research on the relationship between entrepreneurship, financial performance and enterprise growth -- Taking the IPO data of science and technology innovation board as an example [J]. Friends of accounting, 2020 (17): 88-92 